\title{
Arctigenin, a Potential Anti-Arrhythmic Agent, Inhibits Aconitine-Induced Arrhythmia by Regulating Multi-Ion Channels
}

\author{
Zhenying Zhao a,c,e Yongqiang Yin ${ }^{b, e}$ Hong Wu ${ }^{b, d}$ Min Jiang ${ }^{a}$ Jianshi Lou ${ }^{b}$ Gang Baia \\ Guo'an Luo \\ aCollege of Pharmacy, Nankai University, bepartment of Pharmacology, Tianjin Medical University, \\ 'Department of Pharmacy, Tianjin Union Medical Center, Tianjin, ${ }^{\mathrm{d} C e n t e r}$ of Functional Experiment \\ Teaching and Key Laboratory of Cancer Prevention Research, Mudanjiang Medical College, \\ Mudanjiang, Heilongjiang, P.R. China; eThese authors contributed equally
}

\section{Key Words}

Arctigenin • Arrhythmia • Ion channel • Patch clamp • Aconitine

\begin{abstract}
Background/Aims: Arctigenin possesses biological activities, but its underlying mechanisms at the cellular and ion channel levels are not completely understood. Therefore, the present study was designed to identify the anti-arrhythmia effect of arctigenin in vivo, as well as its cellular targets and mechanisms. Methods: A rat arrhythmia model was established via continuous aconitine infusion, and the onset times of ventricular premature contraction, ventricular tachycardia and death were recorded. The Action Potential Duration (APD), sodium current $\left(I_{\mathrm{Na}}\right)$, L-type calcium current $\left(I_{\mathrm{Ca}, \mathrm{L}}\right)$ and transient outward potassium current $\left(I_{\text {to }}\right)$ were measured and analysed using a patch-clamp recording technique in normal rat cardiomyocytes and myocytes of arrhythmia aconitine-induced by. Results: Arctigenin significantly delayed the arrhythmia onset in the aconitine-induced rat model. The $50 \%$ and $90 \%$ repolarisations $\left(\mathrm{APD}_{50}\right.$ and $A \mathrm{AP}_{90}$ ) were shortened by $100 \mu \mathrm{M}$ arctigenin; the arctigenin dose also inhibited the prolongation of $\mathrm{APD}_{50}$ and $\mathrm{APD}_{90}$ caused by $1 \mu \mathrm{M}$ aconitine. Arctigenin inhibited $I_{\mathrm{Na}}$ and $I_{\mathrm{Ca}, \mathrm{L}}$ and attenuated the aconitine-increased $I_{\mathrm{Na}}$ and $I_{\mathrm{Ca}, \mathrm{L}}$ by accelerating the activation process and delaying the inactivation process. Arctigenin enhanced $I_{\text {to }}$ by facilitating the activation process and delaying the inactivation process, and recoverd the decreased $I_{\text {to }}$ induced by aconitine. Conclusions: Arctigenin has displayed anti-arrhythmia effects, both in vivo and in vitro. In the context of electrophysiology, $I_{\mathrm{Na}^{\prime}} I_{\mathrm{Ca}^{\prime} \mathrm{L}^{\prime}}$ and $I_{\text {to }}$ may be multiple targets of arctigenin, leading to its antiarrhythmic effect.




\section{Introduction}

The antiarrhythmic effects of agents commonly used in the clinic act by blocking sodium [1], potassium [2] and calcium ion channels [3]. However, blocking these channels may also cause proarrhythmias [4], which arouses concerns. Therefore, recent studies are focused on finding new targets and new mechanisms for arrhythmias.

Malfunctioning ion channels during the pathological state are crucial for arrhythmia induction. Recovering the unbalanced ion currents by regulating ion channel equilibrium may help mitigate arrhythmias. Antiarrhythmic agents correct ion transport disorders across the membrane of myocardial cells through different mechanisms. Aconitine is an alkaloid extracted from Aconitum, Radix Aconiti Kusnezoffii or Radix Aconiti Lateralis Preparata that may provoke ventricular arrhythmias in rats [5]. In addition, aconitine led to "arrhythmias" at the cellular level that can be used as a model while screening antiarrhymic drugs [6]. The targets of aconitine include APD, $I_{\mathrm{Na}} I_{\mathrm{Ca}, \mathrm{L}}$, and $I_{\mathrm{to}}$; these targets may be critically involved in both arrhythmic and antiarrhythmic processes. Arctigenin, a lignan extract from Fructus Arctii, the dried fruit of Arctium Lappa L. (Compositae), reportedly possesses anti-inflammatory, immunomodulatory, antiviral, antitumor, antioxidant, vasodilatory and anti-platelet-aggregation properties [7]. Nevertheless, little is known about the effects of arctigenin on the ion channels of rat ventricular myocytes exposed to aconitine. Accordingly, in this study we investigated the anti-arrhythmic effect of arctigenin in vivo, as well as the cellular mechanism of action in rat cardiomyocytes with aconitine-induced arrhythmias.

\section{Materials and Methods}

\section{Animals}

Wistar rats (250-300 g, half male and half female) were purchased from Beijing Vital River Laboratory Animal Technology Co., Ltd (Beijing, China) and housed at $22 \pm 2{ }^{\circ} \mathrm{C}$ with $55 \pm 10 \%$ humidity, a $12 \mathrm{~h}$ light/ dark cycle, and free access to food and tap water. All experiments were carried out according to the Guide for the Care and Use of Experimental Animals. The studies were approved by the Institute Committee of the Animal Care of Nankai University and Tianjin Medical University.

\section{Chemicals}

Arctigenin and aconitine were obtained from the National Institute for Food and Drug Control (Beijing, China). The arctigenin was dissolved in DMSO to prepare a $0.1 \mathrm{M}$ stock solution. HEPES, taurine, $\mathrm{Na}_{2}-$ ATP, Mg-ATP, aspartate, K-asparate, egtazic acid (EGTA), tris base and creatine phosphate disodium were purchased from Sigma-Aldrich (St. Louis., MO, USA). Collagenase (type II) and bovine serum albumin (BSA) were purchased from Invitrogen (Carlsbad, CA, USA). All other reagents were of analytical grade.

\section{Solutions [8]}

The Tyrode's solution contained (mM): $\mathrm{NaCl} 126, \mathrm{KCl} 5.4, \mathrm{MgCl}_{2} 1, \mathrm{CaCl}_{2} 1.8, \mathrm{NaH}_{2} \mathrm{PO}_{4} 0.33$, glucose 10 and HEPES 10 (pH 7.4 adjusted with $\mathrm{NaOH}$ ). The $\mathrm{Ca}^{2+}$-free Tyrode's solution was prepared by removing $\mathrm{CaCl}_{2}$ from the Tyrode's solution. The Kreb's solution used for cell storage contained (mM): glutamic acid 70, taurine $15, \mathrm{KCl} 30, \mathrm{KH}_{2} \mathrm{PO}_{4} 10, \mathrm{MgCl}_{2} 0.5$, EGTA 0.5, HEPES 10, glucose 10, and $1 \%$ albumin (pH 7.4 adjusted with $\mathrm{KOH}$ ). The enzyme solution used for the rat cardiomyocyte isolation contained $0.1 \mathrm{~g} / \mathrm{L}$ collagenase (type II) and $0.5 \mathrm{~g} / \mathrm{L} \mathrm{BSA}$ in Kreb's solution. The standard bath solution for recording $I_{c a, L}$ contained (mM): Tris-Cl 136, CsCl 5.4, $\mathrm{MgCl}_{2}$ 1, $\mathrm{CaCl}_{2}$ 2, glucose 10, and HEPES 10, (pH 7.4 adjusted with Tris-OH). The pipette solution for recording $I_{c a, L}$ contained (mM): $\mathrm{CsOH} \mathrm{110,} \mathrm{CsCl} 20$, aspartate 110, $\mathrm{MgCl}_{2} 1$, HEPES 5, EGTA 10, and Mg-ATP 5 (pH 7.2 adjusted with $\mathrm{CsOH}$ ). The standard bath solution for recording $I_{N a}$ contained (mM): choline chloride 120, $\mathrm{NaCl} 25, \mathrm{CsOH} 4, \mathrm{CaCl}_{2} 0.1, \mathrm{CoCl}_{2} 2, \mathrm{MgCl}_{2} 1, \mathrm{HEPES} 10$ and glucose 10 (pH 7.4 adjusted with $\mathrm{CsOH}$ ). The pipette solution for recording $I_{N a}$ contained (mM): CsOH 140, NaCl 10, EGTA 5, Na 2 -ATP 5 and HEPES 5 (pH 7.3 adjusted with $\mathrm{CsOH}$ ). The standard bath solution for recording $I_{\text {to }}$ contained (mM): choline chloride 137, $\mathrm{KCl} 5.4, \mathrm{MgCl}_{2}$ 1, $\mathrm{Na}_{2}$-ATP 0.33, HEPES 10 and glucose 10 (pH 7.4 adjusted with LiOH). The pipette solution for recording $I_{\text {to }}$ contained (mM): K-asparate 120, KC1 20, HEPES 5, $\operatorname{MgCl}_{2} 1, \mathrm{~K}_{2}$-ATP 4, EGTA 10 and creatine phosphate disodium 2 (pH 7.3 adjusted with $\mathrm{KOH}$ ). 


\section{Establishment of the arrhythmic model}

Wistar rats were anesthetised with $25 \%$ urethane $(0.4 \mathrm{~g} / 100 \mathrm{~g})$. The Lead II electrocardiograms (ECGs) were recorded with a BL-420S Biological Data Acquisition \& Analysis System (Chengdu Technology \& Market Corp. Ltd, China). The ECGs were measured as described which was only measured in beats that originated from the sino-atrial node [9]. Normal Saline (N.S.), arctigenin solution (2 mM, $1 \mathrm{mM})$ and vehicle solution (1\% DMSO) were administrated continuously through superficial femoral vein at a velocity of $0.1 \mathrm{ml} / \mathrm{min}$ for $8 \mathrm{~min}$. After stabilisation for $5 \mathrm{~min}$, aconitine $(10 \mu \mathrm{g} / \mathrm{ml})$ was infused continuously at the same speed. The ECGs of the different groups were recorded with the onset time of ventricular premature contraction (VP), ventricular tachycardia (VT) and death.

\section{Cell preparations}

Single ventricular myocytes were isolated from adult rat hearts via enzymatic dissociation as previously described [10]. Briefly, the rats were anesthetised with $25 \%$ urethane $(0.4 \mathrm{~g} / 100 \mathrm{~g})$. Their hearts were excised rapidly and retrogradely perfused on a Langendorff apparatus with a $\mathrm{Ca}^{2+}$-free Tyrode's solution for $5 \mathrm{~min}$ before the perfusate was switched to an enzymatic solution for $15 \mathrm{~min}$. The perfusate was finally changed to Kreb's solution for $5 \mathrm{~min}$. The perfusates were bubbled with $95 \% \mathrm{O}_{2}+5 \% \mathrm{CO}_{2}$ and maintained at $37^{\circ} \mathrm{C}$. The ventricles were cut into small chunks and gently agitated in Kreb's solution. The cells were filtered through nylon mesh (pore size $200 \mu \mathrm{m}$ ) and stored in Kreb's solution at $4{ }^{\circ} \mathrm{C}$.

\section{Recording of action potentials}

Action potentials were elicited at $1 \mathrm{~Hz}$ by $2 \mathrm{~ms}$ current pulses applied using the patch pipette. The action potential durations at $50 \%$ and $90 \%$ repolarisation $\left(\mathrm{APD}_{50}\right.$ and $\left.\mathrm{APD}_{90}\right)$, resting membrane potential $\left(\mathrm{V}_{\mathrm{m}}\right)$, and overshot (OS) were measured.

\section{Whole cell patch clamp recording}

Cell suspensions were transferred into a chamber on the stage of an Olympus IX51 inverted microscope (Tokyo, Japan). The whole-cell recordings were performed using isolated single ventricular myocytes. Glass microelectrodes were constructed with a Model P-97 microelectrode puller (Sutter Instrument Co, USA) by two-stage pulling and had a resistance of 3.0-8.0 $\mathrm{M} \Omega$ when filled with the internal electrode solution. The sodium currents, L-type calcium currents and potassium currents were recorded with an Axopatch 700B amplifer (Axon Instruments, Foster City, CA, USA) and digitised at 2-10 kHz with an analogue-to-digital Digit Data $1440 \mathrm{~A}$ converter. The pCLAMP 10.0 software was used to generate voltage clamp protocols, acquire data, and analyse the current traces. The whole-cell series resistance was compensated to more than $80 \%$. Current traces were presented by current density (pA/pF). All of the experiments were performed at room temperature $\left(23 \pm 1^{\circ} \mathrm{C}\right)$. The whole-cell $I_{\mathrm{Na}}$ was elicited from a $-90 \mathrm{mV}$ holding potential to test potentials from -90 to $+25 \mathrm{mV}$ in $5 \mathrm{mV}$ increments. The $I_{\mathrm{Na}}$ was calculated as the difference between the peak inward current and the holding current level. The whole-cell $I_{\mathrm{Ca}, \mathrm{L}}$ was elicited from a $-50 \mathrm{mV}$ holding potential to test potentials from -50 to $+65 \mathrm{mV}$ in $5 \mathrm{mV}$ increments. The $I_{\mathrm{Ca}, \mathrm{L}}$ was calculated as the difference between the peak inward current and the holding current level. The whole-cell $I_{\text {to }}$ was elicited from a -50 mV holding potential to test potentials from -50 to $+65 \mathrm{mV}$ in $5 \mathrm{mV}$ increments.

\section{Statistics}

The data were presented as the Mean \pm SD. The curves were fitted with pCLAMP 10.0 (Axon Instruments) and software Origin 6.0. The statistical significance was determined using a $t$-test when comparing two groups and ANOVA when comparing multiple groups. A value of $P<0.05$ was considered statistically significant.

\section{Results}

Effect of arctigenin on arrhythmias induced by aconitine

In the vehicle group, aconitine $(10 \mu \mathrm{g} / \mathrm{ml})$ induced arrhythmias shortly after infusion at $0.1 \mathrm{ml} / \mathrm{min}$; the onset times of VP, VT and death were $3.78 \pm 0.93 \mathrm{~min}, 4.65 \pm 0.91 \mathrm{~min}$ and $16.32 \pm 1.02 \mathrm{~min}$, respectively. Arctigenin pre-treatment significantly delayed the onset of aconitine-induced arrhythmias in a concentration-dependent manner. In $1 \mathrm{mM}$ arctigenin 
Table 1. Effects of arctigenin on APD, resting potential and overshot in rat ventricular myocytes. RP: Resting potential; OS: Overshot; $\mathrm{APD}_{50}$ : Action potential duration (APD) at $50 \%$ repolarisation; $\mathrm{APD}_{90}$ : Action potential duration (APD) at $90 \%$ repolarisation; N.B.: $1 \mu \mathrm{M}$ Acon $+100 \mu \mathrm{M}$ Arc. ${ }^{*} P<0.05$ vs Control; ${ }^{* *} P<0.01$ vs. Control (Mean $\pm \mathrm{SD}, \mathrm{n}=4$ )

\begin{tabular}{cccccc}
\hline Group & $\begin{array}{c}\text { Concentration } \\
(\mu \mathrm{M})\end{array}$ & $\begin{array}{c}\mathrm{RP} \\
(\mathrm{mV})\end{array}$ & $\begin{array}{c}\text { OS } \\
(\mathrm{mV})\end{array}$ & $\begin{array}{c}\text { APD } \\
(\mathrm{ms})\end{array}$ & $\begin{array}{c}\text { APD } \\
(\mathrm{ms})\end{array}$ \\
\hline Control & Tyrode's solution & $-75.9 \pm 2.81$ & $38.3 \pm 2.43$ & $86.1 \pm 2.48$ & $143.5 \pm 7.8$ \\
Arc & 1 & $-76.3 \pm 5.72$ & $36.4 \pm 4.62$ & $85.6 \pm 2.91$ & $140.4 \pm 9.9$ \\
& 10 & $-78.8 \pm 5.37$ & $31.5 \pm 3.56^{*}$ & $84.1 \pm 3.71$ & $135.2 \pm 12.1$ \\
& 100 & $-80.7 \pm 4.76$ & $28.9 \pm 2.36^{* *}$ & $82.9 \pm 2.8$ & $120.0 \pm 9.6^{* *}$ \\
Acon & 1 & $-60.8 \pm 2.28^{* *}$ & $45.9 \pm 4.2^{*}$ & $146.4 \pm 12.53^{* *}$ & $224.8 \pm 16.2^{* *}$ \\
Acon+ Arc & N.B. & $-77.9 \pm 4.05$ & $40.1 \pm 3.8$ & $93.2 \pm 6.5$ & $165.3 \pm 13.1^{*}$ \\
\hline
\end{tabular}

Fig. 1. Onset time of arrhythmias among different groups after continuous aconitine administration through the femoral vein (Means \pm SD, $\mathrm{n}=6)$. In the vehicle (1\% DMSO) group, aconitine $(10 \mu \mathrm{g} / \mathrm{ml})$ induced arrhythmias shortly after infusion began at $0.1 \mathrm{ml} / \mathrm{min}$, while the arctigenin pre-treatment significantly prolonged the onset of the aconitine-induced arrhythmias in a concentration-dependent manner $(1 \mathrm{mM}$, $2 \mathrm{mM}$ ). There were significant differences between the onset time of VP, VT and death between the vehicle group and the arctigenin pretreated groups $\left({ }^{* *} P<0.01\right)$. Arc: arctigenin; Acon: aconitine; VP: ventricular premature contraction; VT: ventricular tachycardia.

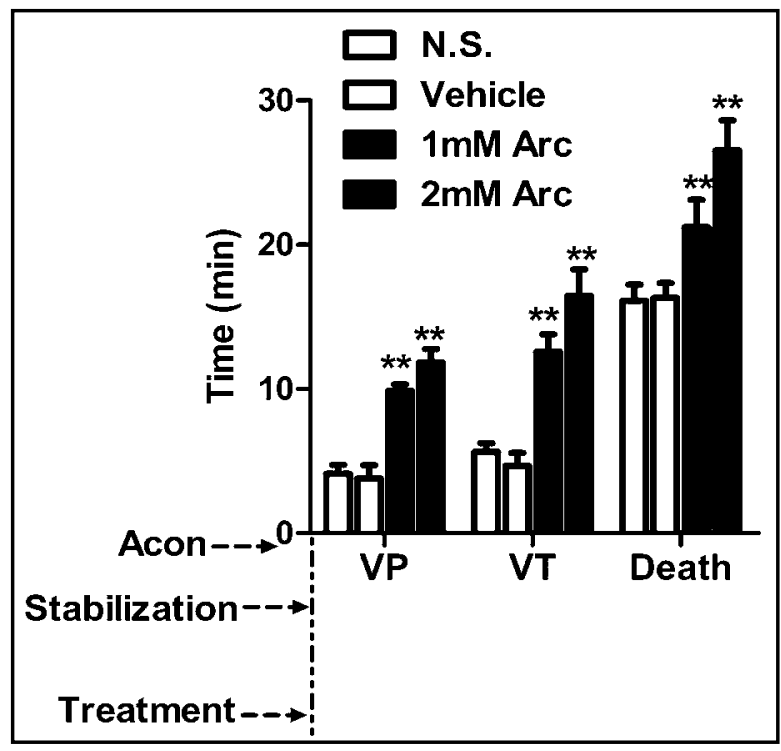

pretreated group, the onset times of VP, VT and death were $9.87 \pm 0.44 \mathrm{~min}, 12.58 \pm 1.20 \mathrm{~min}$ and $21.22 \pm 1.89 \mathrm{~min}$, respectively. In $2 \mathrm{mM}$ arctigenin pretreated group, the onset times of VP, VT and death were $11.83 \pm 0.93 \mathrm{~min}, 16.47 \pm 1.81 \mathrm{~min}$ and $26.55 \pm 2.06 \mathrm{~min}$, respectively. There were significant differences between the vehicle group and arctigenin pre-treated groups $(P<0.01)$ (Fig. 1).

\section{Effects of arctigenin on APD}

To evaluate the effects of arctigenin, the action potential was recorded before and after the arctigenin treatments of rat ventricular myocytes driven at $1 \mathrm{~Hz}$. Aconitine prolonged the action potential duration at $50 \%$ and $90 \%$ repolarisation $\left(\mathrm{APD}_{50}\right.$ and $\left.\mathrm{APD}_{90}\right)$ which were attenuated by $100 \mu \mathrm{M}$ arctigenin treatment. The cell membrane was hyperpolarised by 100 $\mu \mathrm{M}$ arctigenin, and the resting potential changed from $-75.9 \pm 2.81 \mathrm{mV}$ to $-80.7 \pm 3.76 \mathrm{mV}$. Both the $\mathrm{APD}_{50}$ and $\mathrm{APD}_{90}$ were shortened by $100 \mu \mathrm{M}$ arctigenin (Table 1).

\section{Effects of arctigenin on the sodium currents}

Compared to the control group, arctigenin inhibited $I_{\mathrm{Na}}$ with current-voltage curve moving upward (Fig. 2). Arctigenin $(100 \mu \mathrm{M})$ delayed the activation process $(P<0.05)$ but had no effect on inactivation process. In contrast, aconitinine $(1 \mu \mathrm{M})$ increased $I_{\mathrm{Na}}$ by facilitating the activation process and delaying the inactivation process (Fig. 3). The steady- 


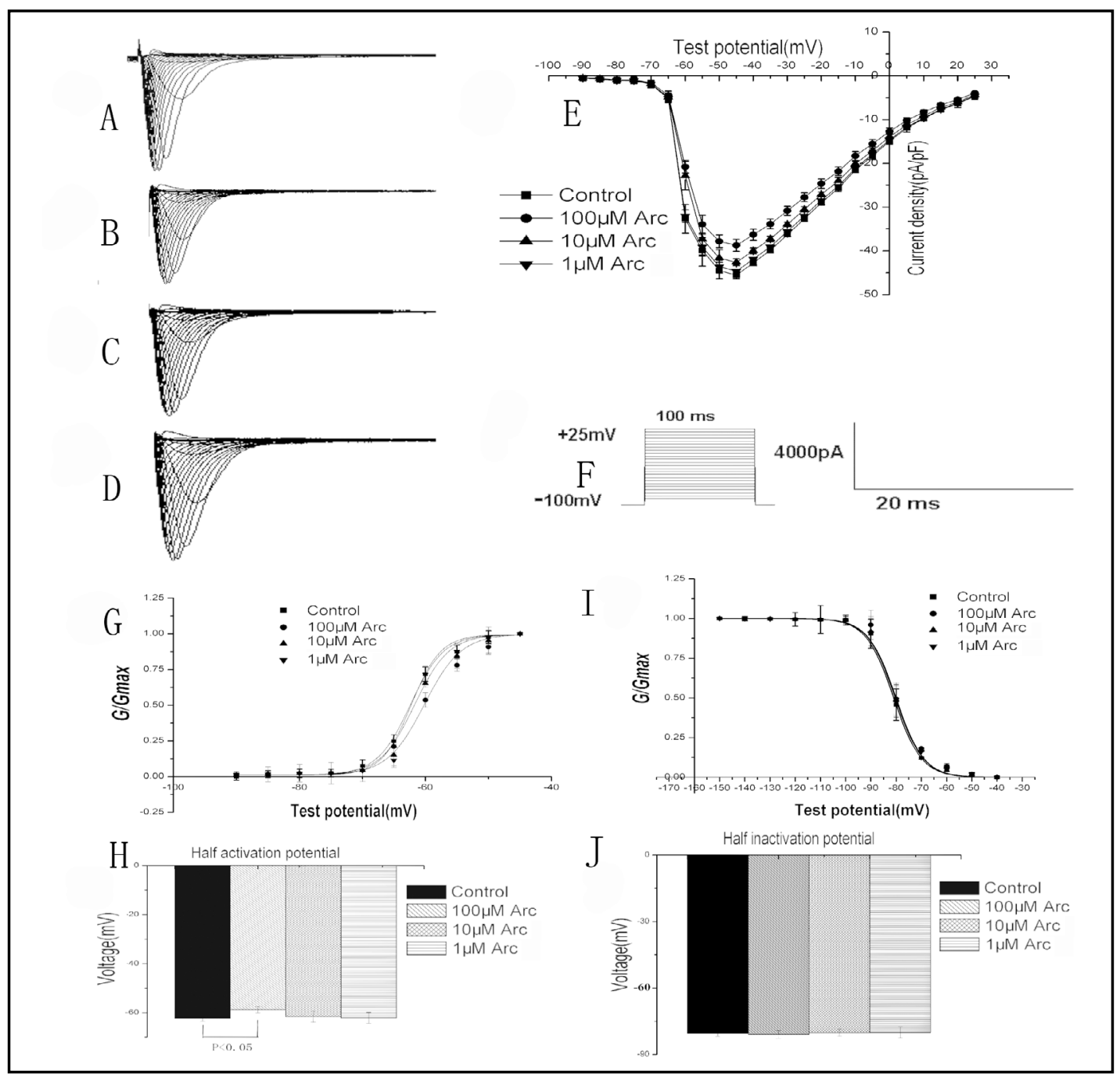

Fig. 2. Arctigenin inhibited the sodium current in rat ventricular cells (Mean $\pm S D, n=8$ ). Compared to control group (A), arctigenin inhibited sodium current with a downward-shift in current-voltage curve (E) by accelerating the activation process $(\mathrm{G})$ and leaving inactivation process intact (I). A: $I_{\mathrm{Na}}$ recorded for the control; B: $I_{\mathrm{Na}}$ recorded at $100 \mu \mathrm{M}$ Arc; C: $I_{\mathrm{Na}}$ recorded at $10 \mu \mathrm{M}$ Arc; D: $I_{\mathrm{Na}}$ recorded at $1 \mu \mathrm{M} \mathrm{Arc;} \mathrm{E:} \mathrm{Arc} \mathrm{current-voltage}$ curve of $I_{\mathrm{Na}}$ in different groups; F: Scale; G: $I_{\mathrm{Na}}$ Steady-state activation curve; H: Half activation potential of different groups; I: $I_{\mathrm{Na}}$ Steady-state inactivation curves; J: Half inactivation potential of different groups. Arc: arctigenin; Acon: aconitine.

state activation and inactivation curves of aconitinine were both shifted toward the left with the $V_{1 / 2}$ of activation and inactivation changed from $-62.25 \pm 1.24 \mathrm{mV}$ and $-80.44 \pm 1.27$ $\mathrm{mV}$ to $-65.79 \pm 1.21 \mathrm{mV}(P<0.05)$ and $-71.41 \pm 1.67 \mathrm{mV}(P<0.01)$, respectively; however, arctigenin $(100 \mu \mathrm{M})$ changed the $\mathrm{V}_{1 / 2}$ of activation and inactivation to $-60.04 \pm 1.38 \mathrm{mV}(P<$ $0.05)$ and $-71.85 \pm 1.71 \mathrm{mV}(P>0.05)$, respectively.

\section{Effects of arctigenin on the L-type calcium currents}

Compared to the control group, arctigenin $(100,10$ and $1 \mu \mathrm{M})$ inhibited $I_{\mathrm{Ca}, \mathrm{L}}$ by delaying the activation process; the half activation potentials were $-6.24 \pm 1.42 \mathrm{mV}{ }^{(L}(P<$ $0.01),-9.12 \pm 1.54 \mathrm{mV}(P>0.05)$ and $-9.64 \pm 1.51 \mathrm{mV}(P>0.05)$ vs $-9.65 \pm 1.50 \mathrm{mV}$ in control group (Fig. 4). However, the inactivation process remained unchanged: $-22.32 \pm 1.65 \mathrm{mV}$, $-22.36 \pm 1.85 \mathrm{mV}$ and $-22.38 \pm 1.56 \mathrm{mV}(P>0.05 \mathrm{vs}$ control $)$. Aconitinine $(1 \mu \mathrm{M})$ increased $I_{\mathrm{Ca}, \mathrm{L}}$ by accelerating the activation process and delaying the inactivation process (Fig. 5). The 


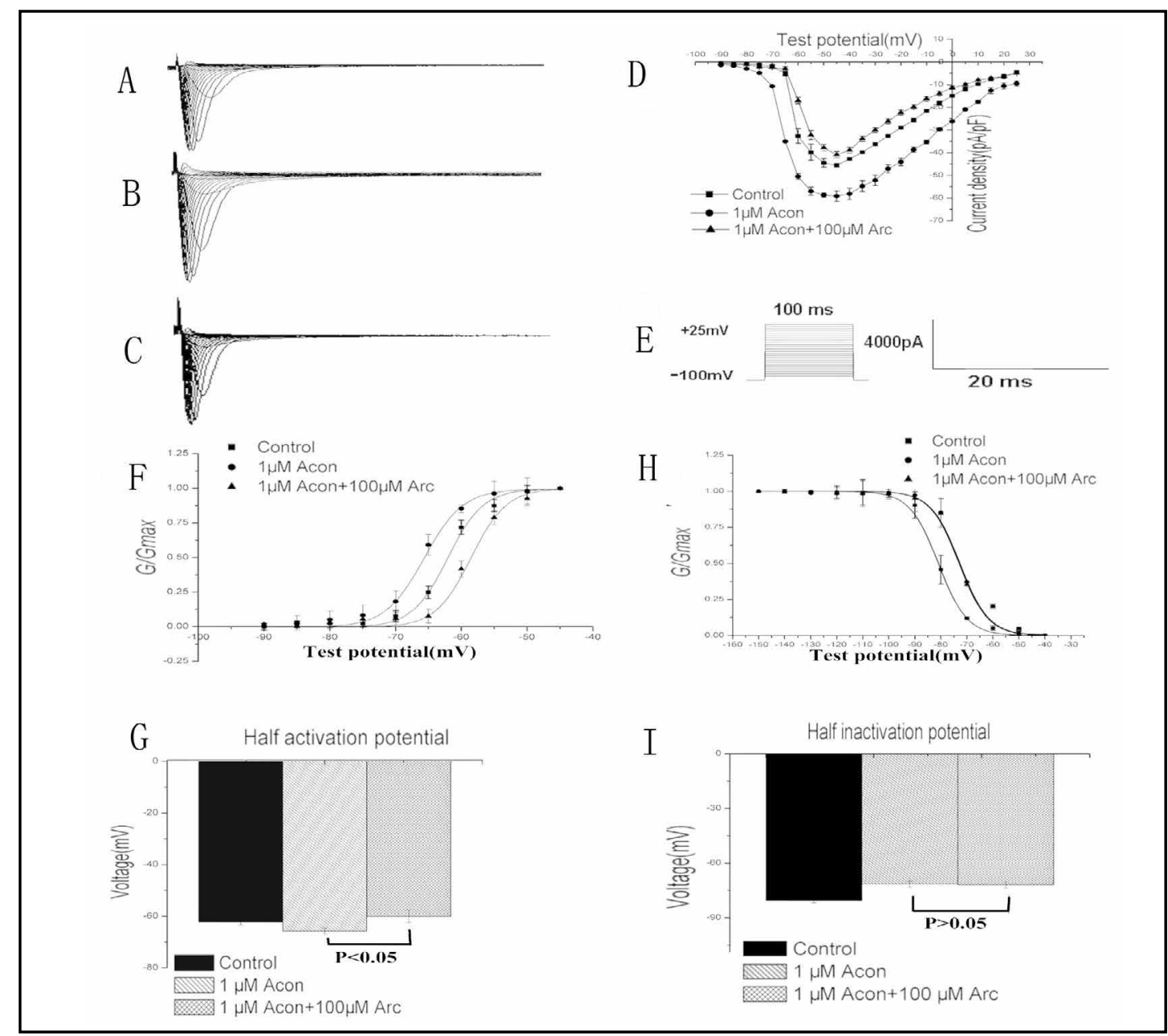

Fig. 3. Arctigenin inhibited the aconitine-induced increase in sodium current in rat ventricular cells (Means \pm SD, $n=8$ ). Aconitine increased the sodium current (C) compared with Control group (A) with a downward-shift in the current-voltage curve (D) by accelerating the activation process (F) and delaying the inactivation process $(\mathrm{H})$. Arctigenin inhibited the increased sodium current $(\mathrm{B})$ by delaying the activation process (F). A: $I_{\mathrm{Na}}$ recorded for the control; B: $I_{\mathrm{Na}}$ recorded in the Acon+Arc group; C: $I_{\mathrm{Na}}$ recorded in the Acon group; D: Current-voltage curve of $I_{\mathrm{Na}}$ in different groups; E: Scale; F: $I_{\mathrm{Na}}$ Steady-state activation curve; G: Half activation potential of different groups; $\mathrm{H}: I_{\mathrm{Na}}$ Steady-state inactivation curves; I: Half inactivation potential of different groups. Arc: arctigenin; Acon: aconitine.

steady-state activation and inactivation curves were both shifted toward the left; the $V_{1 / 2}$ of activation and inactivation changed from $-9.65 \pm 1.51 \mathrm{mV},-22.35 \pm 1.59 \mathrm{mV}$ to $-13.58 \pm 1.45 \mathrm{mV}$ $(P<0.01)$ and $-16.89 \pm 1.98 \mathrm{mV}(P<0.01)$, respectively. Concurrently, the treatment with 100 $\mu \mathrm{M}$ arctigenin changed the $\mathrm{V}_{1 / 2}$ of activation and inactivation to $-6.24 \pm 1.43 \mathrm{mV}(P<0.01)$ and $-17.39 \pm 0.76 \mathrm{mV}(P>0.05)$, respectively.

\section{Effects of arctigenin on the transient outward potassium currents}

Arctigenin enhanced the transient outward potassium current by facilitating the activation process and delaying the inactivation process (Fig. 6). The current-voltage curves were shifted upward, and the current density at $+50 \mathrm{mV}$ was changed from $25.74 \pm 1.51$ $\mathrm{pA} / \mathrm{pF}$ to $30.89 \pm 1.35 \mathrm{pA} / \mathrm{pF}(P<0.01), 27.29 \pm 1.45 \mathrm{pA} / \mathrm{pF}$, and $26.25 \pm 1.25 \mathrm{pA} / \mathrm{pF} .1$ $\mu \mathrm{M}$ aconitine inhibited $I_{\text {to }}$ by delaying the activation process and facilitating the inactivation process; the half activation and inactivation potentials were changed from $-19.33 \pm 0.75 \mathrm{mV}$ and $-3.25 \pm 0.56 \mathrm{mV}$ to $26.39 \pm 0.93 \mathrm{mV}(P<0.01)$ and $-5.15 \pm 0.55 \mathrm{mV}$, repsectively $(P<$ 


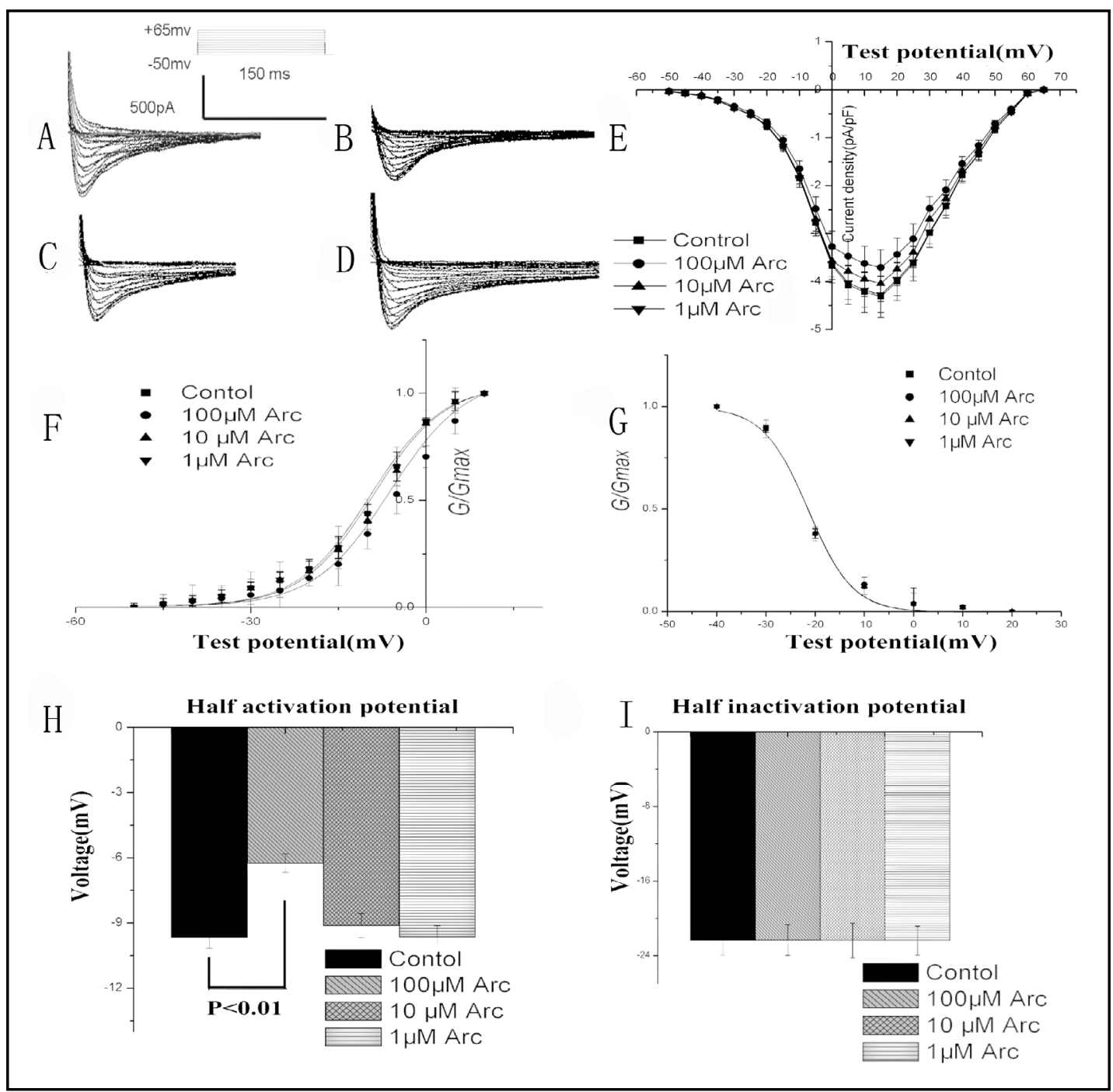

Fig. 4. Arctigenin inhibited the calcium current in rat ventricular cells (Mean $\pm S D, n=8$ ). Arctigenin inhibited the calcium current (B) by accelerating the activation process (F) and leaving the inactivation process unaffected (G), leading to an upward-shift in the current-voltage curve (E). A: $I_{\mathrm{Ca}, \mathrm{L}}$ recorded for the control; $\mathrm{B}: I_{\mathrm{Ca}, \mathrm{L}}$ recorded at $100 \mu \mathrm{M}$ Arc; C: $I_{\mathrm{Ca}, \mathrm{L}}$ recorded at $10 \mu \mathrm{M}$ Arc; D: $I_{\mathrm{Ca}, \mathrm{L}}$ recorded at $1 \mu \mathrm{M}$ Arc; E: Arc Currentvoltage curve of $I_{\mathrm{Ca}, \mathrm{L}}$ in different groups; F: $I_{\mathrm{Ca}, \mathrm{L}}$ Steady-state activation curve; G: Half activation potential of different groups; H: $I_{\mathrm{Ca}, \mathrm{L}}$ Steady-state inactivation curves; I: Half inactivation potential of different groups. Arc: arctigenin; Acon: aconitine.

$0.01)$ (Fig. 7). Arctigenin $(100 \mu \mathrm{M})$ recovered the decreased $I_{\text {to }}$ induced by aconitine with half activation potential and half inactivation potential changing to $18.76 \pm 0.99 \mathrm{mV}(P<0.01)$ and $-3.23 \pm 0.76 \mathrm{mV}(P<0.05)$, respectively.

\section{Discussion}

This study demonstrated the anti-arrhythmia effects of arctigenin in vivo and in vitro; treatment with arctigenin could correct the aconitine-induced abnormal $I_{\mathrm{Na}} I_{\mathrm{Ca}, \mathrm{L}}$ and $I_{\mathrm{to}}$ by inhibiting the $I_{\mathrm{Na}}$ and $I_{\mathrm{C}, \mathrm{L}}$ and enhancing the $I_{\mathrm{to}}$.

Heart disease remains a major threat to human health. Ideal antiarrhythmic drugs should focus on targeting both multiple- and non-channel targets [11]. Multi-channel effectors 


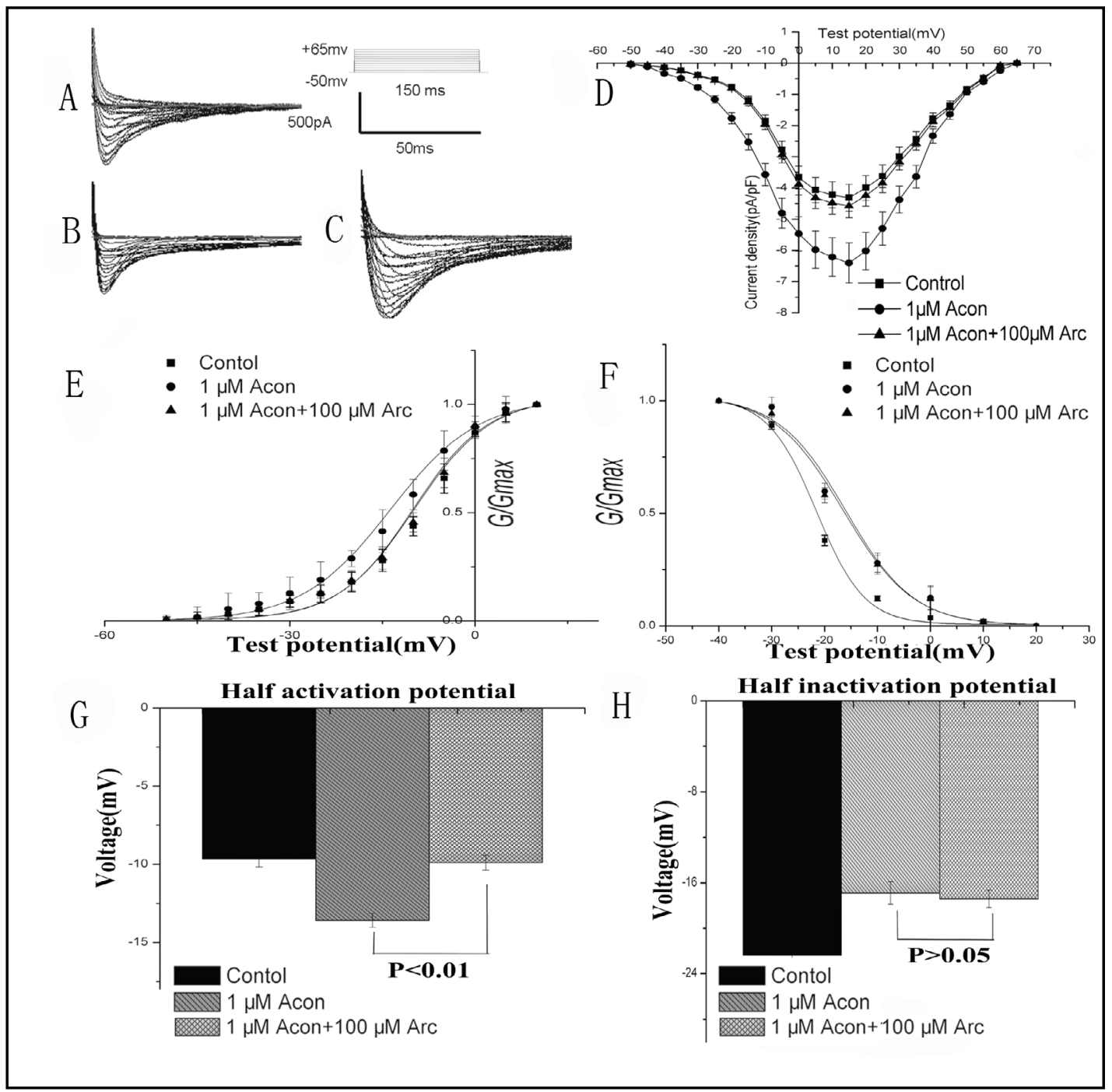

Fig. 5. Arctigenin inhibited the aconitine-induced increase in calcium current in rat ventricular cells $($ Mean \pm SD, $n=8$ ). Aconitine increased the calcium current (B) by accelerating the activation process (E) and delaying the inactivation process (F), leading to downward-shift in the current-voltage curve (D). Arctigenin inhibited the increase in calcium current $(\mathrm{C})$ by delaying the activation process $(\mathrm{E})$. A: $I_{\mathrm{Ca}, \mathrm{L}}$ recorded for the control; B: $I_{\mathrm{Ca}, \mathrm{L}}$ recorded in the Acon+Arc group; C: $I_{\mathrm{Ca}, \mathrm{L}}$ recorded in Acon group; D: Current-voltage curves for $I_{\mathrm{Ca}, \mathrm{L}}$ in different groups; E: $I_{\mathrm{Ca}, \mathrm{L}}$ Steady-state activation curves; F: $I_{\mathrm{Ca}, \mathrm{L}}$ Steady-state inactivation curves; G: Half activation potential of different groups; $\mathrm{H}: I_{\mathrm{Ca}, \mathrm{L}}$ Steady-state inactivation curves. Arc: arctigenin; Acon: aconitine.

regulate ion channels to regain the integrative balance between the various channels and have a lower arrhythmoginic effect than the single channel blockers. The other effects are etiological treatments, myocardial protection, and ventricular remodeling reversion, among others.

Aconitine is a specific sodium channel agonist and can prolong the open state of the channels [12], inducing intracellular $\mathrm{Na}^{+}$accumulation and $\mathrm{Ca}^{2+}$ overload; therefore, exposure to aconitine may eventually cause polymorphic arrhythmias, including ventricular bigeminy, tachycardia and ventricular fibrillation. Consequently, aconitine has been widely used as an experimental tool for inducing cardiac arrhythmias in various animals [13]. We adopted the aconitine-induced arrhythmic rat and cellular models to investigate the anti-arrhythmia effect of arctigenin and the underlying electrophysiological mechanism. In the aconitine- 


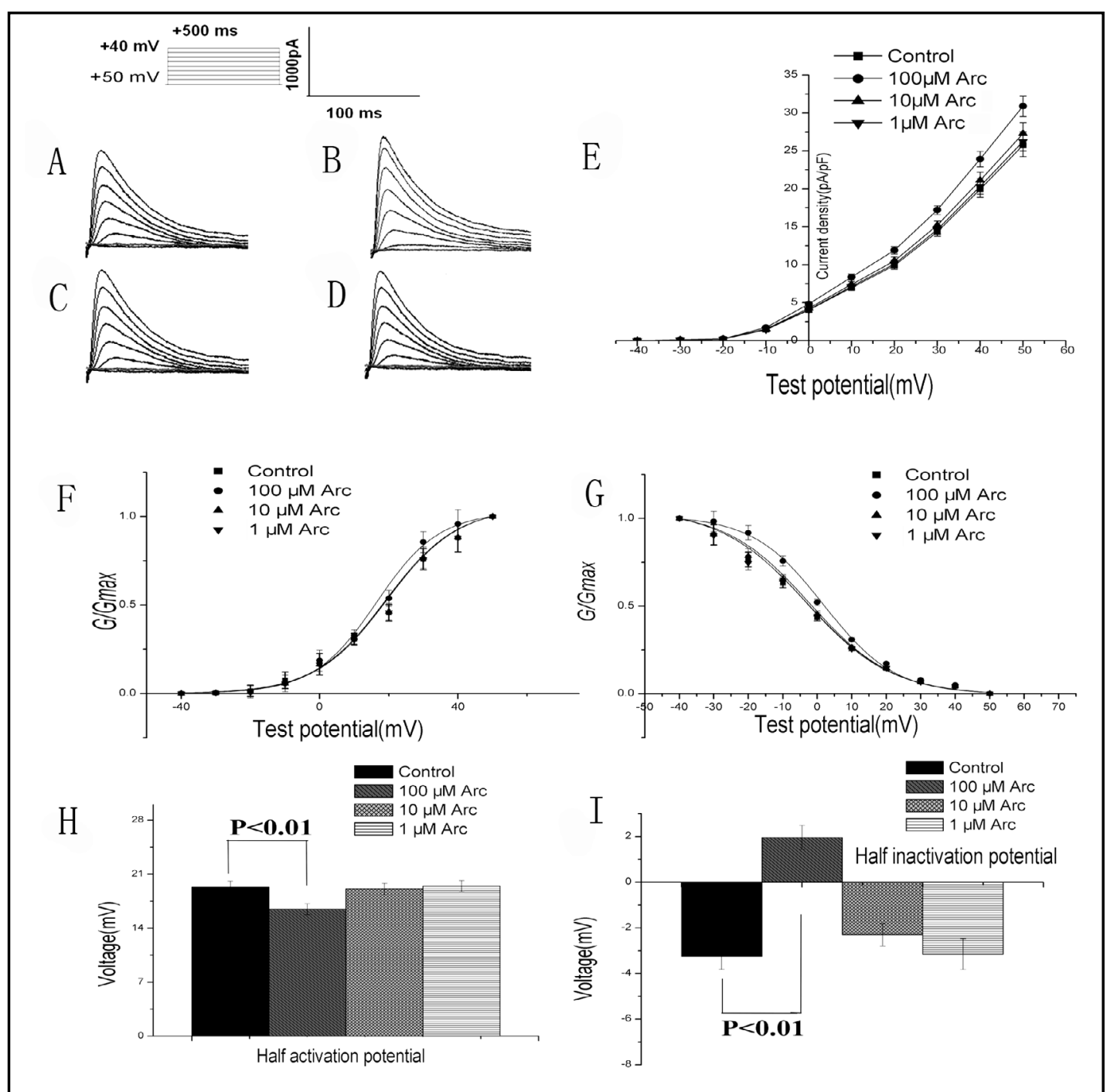

Fig. 6. Arctigenin increased the potassium transient outward current in rat ventricular cells (Mean $\pm S D$, $\mathrm{n}=8)$. A: $I_{\text {to }}$ recorded for the control; B: $I_{\text {to }}$ recorded at $100 \mu \mathrm{M} \mathrm{Arc;} \mathrm{C:} I_{\text {to }}$ recorded at $10 \mu \mathrm{M}$ Arc; D: $I_{\text {to }}$ recorded at $1 \mu \mathrm{M}$ Arc; E: Arc Current-voltage curve for $I_{\text {to }}$ in different groups; F: $I_{\text {to }}$ Steady-state activation curve; G: Half activation potential of different groups; H: $I_{\text {to }}$ Steady-state inactivation curves; I: Half inactivation potential of different groups. Arc: arctigenin; Acon: aconitine.

induced rat arrhythmia model, aconitine induced arrhythmias shortly after infusion began, while arctigenin pre-treatment significantly delayed the onset of arrhythmias in a concentration-dependent manner, revealing the antiarrhythmic effects of arctigenin in vivo.

The voltage-gated $\mathrm{Na}^{+}$channel is primarily responsible for generating and propagating the action potential (AP) in excitable tissues. In the heart, disturbing the activity of voltagegated sodium channels significantly influences the excitation of cardiomyocytes; this excitation is crucial for the pathogenesis of arrhythmias. When cells are under abnormal conditions, such as injury or hypoxia, the $\mathrm{Na}^{+}$influx leads to intracellular calcium overload via $\mathrm{Na}^{+}-\mathrm{Ca}^{2+}$ exchange, causing the arrhythmias. Aconitine induces arrhythmias by promoting the $\mathrm{Na}^{+}$influx and the autorhythmicity of the ectopic pacemakers $[6,14,15]$. Arctigenin decreased the sodium currents and shifted the voltage-current relationship curve upward, suggesting that arctigenin inhibits sodium channels in rat ventricular myocytes; this conclusion is consistent with the arctigenin-mediated inhibition of the aconitineinduced elevated action potential overshot. The kinetic data for sodium channels indicated 


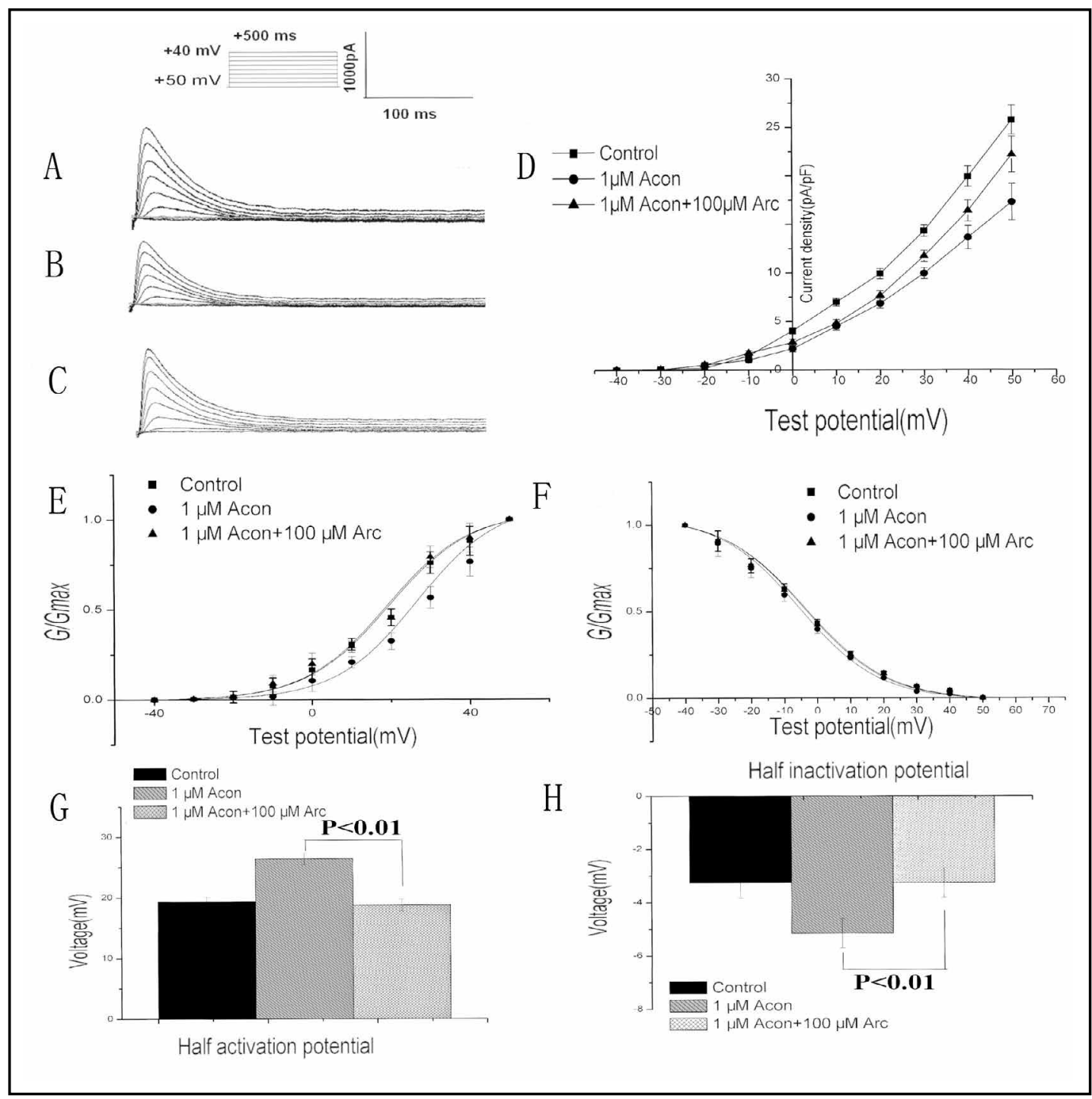

Fig. 7. Arctigenin increased the aconitine-inhibited potassium transient outward current in rat ventricular cells (Mean \pm SD, n=8). Aconitine inhibited $I_{\text {to }}(\mathrm{D})$ by delaying the activation process $(\mathrm{E})$ and precipitating the inactivation process $(\mathrm{F})$, which was reversed by arctigenin. A: $I_{\text {to }}$ recorded as Control; B: $I_{\text {to }}$ recorded in Acon group; C: $I_{\text {to }}$ recorded in Acon+Arc group; D: Current-voltage curves for $I_{\text {to }}$ in different groups; E: $I_{\text {to }}$ Steadystate activation curves; F: $I_{\text {to }}$ Steady-state inactivation curves; G: Half activation potential of different groups; $\mathrm{H}: I_{\text {to }}$ Steady-state inactivation curves. Arc: arctigenin; Acon: aconitine.

that arctigenin shifted the steady-state activation curves toward the right but did not affect the steady-state inactivation curves. Therefore, arctigenin inhibited $I_{\mathrm{Na}}$ by slowing the steady-state activation. However, excessive inhibition of sodium channels may also lead to arrhythmias. For example, quinidine is a sodium channel blocker that exhibits various side effects, including cardiac arrest, conduction blockages and abnormal myocardial excitement. In this study, arctigenin displayed moderate sodium blocking effects, and probably possess lower arrhythmogenic risk.

$I_{\mathrm{C} a \mathrm{~L}}$ is crucial for the depolarisation and repolarisation of action potentials and cellular contraction. The L-type $\mathrm{Ca}^{2+}$ channels in cardiac myocytes are important during the generation of action potentials under physiological and pathophysiological conditions, such as arrhythmias $[16,17]$. Furthermore, the L-type $\mathrm{Ca}^{2+}$ channels play critical roles during 
$\mathrm{Ca}^{2+}$ influx in cardiac cells. Intracellular calcium overload may lead to triggered activity in heart. Arctigenin significantly decreased the aconitine-enhanced $I_{\mathrm{Ca}, \mathrm{L}}$ and shifted the steadystate activation curves toward the right; however, this compound did not affect steady-state inactivation curves. Taken together, these results provided electrophysiological evidence that arctigenin relieved the aconitine-induced abnormal calcium current changes by slowing the steady-state activation.

The $\mathrm{K}^{+}$channel produces $I_{\text {to }}$ and is another target for antiarrhythmic drugs [18-20]. In this study, aconitine inhibited $I_{\text {to }}$, but this effect was alleviated by arctigenin, indicating that arctigenin enhanced the outward potassium current. The enhanced $I_{\text {to }}$ could accelerate the myocardial repolarisation and increase resting membrane potential, subsequently affecting the atrioventricular blockage. However, the increased $I_{\text {to }}$ might enhance hyperpolarisation and reinforce membrane stability, revealing its potential antiarrhythmic action.

Inhibiting inward current by blocking sodium and calcium channels may cause slower conductivity, reduced excitability, sinus-atrium and atrium-ventricle blockades with subsequent bradycardia, contribute to the re-entry by unidirectional blockages or slowed conductivity, or greatly shorten the APD by loss of the plateau in the action potential. In the latter, blocking sodium and calcium channels increases the transmural dispersion of ventricular repolarisation. Inhibiting the repolarisation of the outward currents usually generates a prolonged APD rapidly after depolarisation. However, because the APD is often prolonged with heterogeneity, drugs that inhibit the outward currents normally increase the TDR and eventually cause Torsade de points (TdP) [21]. According to "Principles for Best Targets of Antiarrhythmic Drugs", ion channels on myocardial cell membranes remain balanced under normal conditions. However, there is a risk that the equilibrium may be disturbed if the targeted ion channels on myocardial membrane are affected. An ideal antiarrhythmic drug should have three or more targets and mildly affect each channel. Accordingly, arctigenin demonstrated its mild antiarrhythmic effects and low arrhythmogenic features by harmoniously inhibiting $I_{\mathrm{Na}}$ and $I_{\mathrm{Ca}, \mathrm{L}}$ while increasing $I_{\mathrm{to}}$ in accordance with the above-mentioned principles.

The extracts of the fruits, roots and leaves of Arctium lappa L. can inhibit liposome peroxidation, scavenge the free radicals in myocardial cells and inhibit apoptosis [7, 22, 23]. The anti-inflammatory, fatigue resistance and immunoregulatory effects of arctigenin also contribute to its antiarrhythmic effect. The effects of arctigenin on myocardial cell membrane receptors and enzymes, as well as autonomic nervous function, myocardial autorhythmicity, and conductivity, remain open to further exploration.

In summary, this study provided both in vivo and electrophysiological evidences for the anti-arrhythmia effect of arctigenin; this compound mitigated the disturbances in ion channel function by affecting the currents and the activation/inactivation and action potential of rat myocardial cells. This study laid a foundation for the further investigation and application of the anti-arrhythmic effect displayed by arctigenin.

\section{Conflict of Interests}

The authors declare that they have no competing interests.

\section{Acknowledgements}

This study was financially supported by grants from the National Nature Science Fund (NNSF) of China (No. 81173638, 81373506), and The Ministry of Education Doctoral Fund (No. 20120031110042); Key Teacher Training Project of Heilongjiang Province (1155G61) and Chinese Postdoctoral Fund (20080440687). We appreciate the valuable comments from other members of our laboratories. 


\section{References}

1 Sheets MF, Fozzard HA, Lipkind GM, Hanck DA: Sodium channel molecular conformations and antiarrhythmic drug affinity. Trends Cardiovas Med 2010;20:16-21.

-2 Tosaki A, Szerdahelyi P, Engelman RM, Das DK: Potassium channel openers and blockers: do they possess proarrhythmic or antiarrhythmic activity in ischemic and reperfused rat hearts? J Pharmacol Exp Ther 1993;267:1355-1362.

-3 Apostolakos MJ, Varon ME: Antiarrhythmic and anti-ischemic properties of calcium-channel antagonists. New Horiz 1996;4:45-57.

4 Kowey PR, Yan GX: Proarrhythmias and antiarrhythmias: two sides of the same coin. Heart Rhythm 2005;2:957-959.

-5 Zhou SS, Yang J, Li YQ, Zhao LY, Xu M, Ding YF: Effect of cl- channel blockers on aconitine-induced arrhythmias in rat heart. Exp Physiol 2005;90:865-872.

6 Yang B, Shan H, Zhou Y, Gong D, Dong D, Du Z: Construction of a new model for screening antiarrhythmic drugs. Chin Pharmacol Bull 2003;19:217-221.

7 Wang L, Zhao F, Liu K: Advances in studies on pharmacological effect of arctiin and arctigenin. Chin Trad Herbal Drugs 2008;39:467-470.

-8 Zhao L, Lou JS, Wu H, Yin YQ, Kang Y: Effects of taurine-magnesium coordination compound on ionic channels in rat ventricular myocytes of arrhythmia induced by ouabain. Biol Trace Elem Res 2012;147:275-284.

-9 Metcalf CS, Poelzing S, Little JG, Bealer SL: Status epilepticus induces cardiac myofilament damage and increased susceptibility to arrhythmias in rats. Am J Physiol-Heart C 2009;297:H2120-H2127.

10 Zhao L, Lou J, Wu H, Yin Y, Kang Y: Effects of taurine-magnesium coordination compound on ionic channels in rat ventricular myocytes of arrhythmia induced by ouabain. Biol Trace Elem Res 2012;147:275-284.

11 Jiang W, Tang S: Review on antiarrhythmic effect of traditional chinese medicine targeting multi-ion channels. Chin J Integ Trad West Med 2011;31:858-860.

12 Peper K, Trautwein W: The effect of aconitine on the membrane current in cardiac muscle. Pflugers Archiv Gesamte Physiol Menschen Tiere 1967;296:328-336.

13 Amran S, Hashimoto K, Homma N: Effects of sodium-calcium exchange inhibitors, kb-r7943 and sea0400, on aconitine-induced arrhythmias in guinea pigs in vivo, in vitro, and in computer simulation studies. J Pharmacol Exp Ther 2004;310:83-89.

14 Sawanobori T, Adaniya H, Hirano Y, Hiraoka M: Effects of antiarrhythmic agents and $\mathrm{Mg}^{2+}$ on aconitineinduced arrhythmias. Jpn Heart J 1996;37:709-718.

15 Zhou SS, Yang J, Li YQ, Zhao LY, Xu M, Ding YF: Effect of cl- channel blockers on aconitine-induced arrhythmias in rat heart. Exp Physiol 2005;90:865-872.

16 Hadri L, Hajjar RJ: Calcium cycling proteins and their association with heart failure. Clin Pharmacol Ther 2011;90:620-624.

17 Bers DR, Perez-Reyes E: Ca channels in cardiac myocytes: structure and function in ca influx and intracellular ca release. Cardiovasc Res 1999;42:339-360.

18 Giudicessi JR, Ackerman MJ: Potassium-channel mutations and cardiac arrhythmias-diagnosis and therapy. Nat Rev Cardiol 2012;9:319-332.

19 Shieh CC, Coghlan M, Sullivan JP, Gopalakrishnan M: Potassium channels: molecular defects, diseases, and therapeutic opportunities. Pharmacol Rev 2000;52:557-593.

20 Naebauer M, Kaeaeb S: Potassium channel down-regulation in heart failure. Cardiovasc Res 1998;37:324334.

21 Volders P, Vos MA, Szabo B, Sipido KR, de Groot S, Gorgels A, Wellens H, Lazzara R: Progress in the understanding of cardiac early afterdepolarizations and torsades de pointes: time to revise current concepts. Cardiovasc Res 2000;46:376-392.

22 Wang L, Zhao F, Liu K: Advances in studies on pharmacological effect of arctiin and arctigenin. Chin Trad Herbal Drugs 2008;39:467-470.

23 Zhao Z, Yin Y, Wang Z, Fang R, Wu H, Jiang M, Bai G, Luo GA: Arctigenin exhibits relaxation effect on bronchus by affecting transmembrane flow of calcium. Biol Trace Elem Res DOI 10.1007/s12011-0139839-9. 